\title{
On the Evaluation of Flue Gases Capturing Capacity of Porous Organic Materials
}

\author{
Ruh Ullah', Mert Atilhan ${ }^{1}$, and Cafer T. Yavuz ${ }^{2}$ \\ ${ }^{1}$ Department of Chemical Engineering, Qatar University, Doha, Qatar \\ ${ }^{2}$ EEWS Graduate School, Korean Advanced Institute of Science and Technology (KAIST), Daejeon, Republic of Korea \\ mert.atilhan@qu.edu.qa and yavuz@kaist.ac.kr
}

\section{Extended Abstract}

Integrated Gasification Combined Cycle (IGCC) has been emerged as an efficient alternative to post and oxycombustion systems for power generation with controllable $\mathrm{CO}_{2}$ capture and separation. However, this system operates and requires separation of gases at high pressure prior to combustion which subsequently demands highly stable material for $\mathrm{CO}_{2}$ capture and separation. Pre-combustion flue gas capture has been instigated as an alternative to circumvent the costly procedures of materials regeneration utilized by the energy industry for $\mathrm{CO}_{2}$ capture and separation[1]. Stability of the porous structure and repeated use at high pressure and high temperature are among the essential requirements for the efficient materials to be used for industrial level $\mathrm{CO}_{2}$ separation [2,3]. Herein we report the $\mathrm{CO}_{2}$ adsorption-desorption performance of nanoporous covalent organic polymers (COPs), which can operate efficiently and repeatedly at elevated pressure of 200 bars and above. Since, pre-combustion capture also requires removal of hydrogen along with $\mathrm{CO}_{2}$; therefore, nanoporous COP was also tested for hydrogen removal at high pressure. COP material prepared with simple technique from building block monomers of cyanuric chloride and linked with 1,3-bis(4-piperidinyl)propane has enough surface area and pore volume which makes the material capable to store large quantity of syngas at high temperature and pressure. Results indicated that the newly synthesized COP material can adsorbed exceptionally large quantity of $\mathrm{CO}_{2}$ and very little hydrogen at 200 bars and $35{ }^{\circ} \mathrm{C}$. Additionally, the adsorption isotherm was exactly matched with the desorption isotherm, suggesting the material has excellent adsorption-desorption characteristics. Similarly, the material has shown very stable performance when used repeatedly and alternatively for $\mathrm{CO}_{2}$ and hydrogen after regeneration at $50{ }^{\circ} \mathrm{C}$. The capturing performance of material was also investigated for other gases like methane and nitrogen at various pressures and temperatures. Experimental results revealed that $\mathrm{COP}$ material has exceptional $\mathrm{CO}_{2}$ adsorption efficiency, very good selectivity, and strong stability and can be manufacture with simple techniques. Upon comparing with other materials like hyper cross-linked polymers, amine modified SBA-15[4], poly-benzimidazole activated carbon, and organic networks[5], it was found that covalent organic polymers presented here has exceptionally high $\mathrm{CO}_{2}$ uptake capacity, release very low heat of adsorption and possess very good mass transfer coefficient[6]. Lastly, material is economically viable when it is compared with the commercially available materials and has exceptional performance contrary to monoethanole amine.

\section{References}

[1] C. F. Martin, et al., "Hypercrosslinked organic polymer networks as potential adsorbents for pre-combustion CO2 capture," Journal of Materials Chemistry, vol. 21, no. 14, pp. 5475-5483, 2011.

[2] A. Giuffrida, D. Bonalumi, and G. Lozza, "Amine-based post-combustion CO2 capture in air-blown IGCC systems with cold and hot gas clean-up," Applied Energy, vol. 110, pp. 44-54, 2013.

[3] S. Zulfiqar and M. I. Sarwar, "Probing the potential of polyester for CO2 capture," Journal of Environmental Sciences, vol. 26, no. 7, pp. 1423-1427, 2014.

[4] R. Ullah, et al., "Insights of CO2 adsorption performance of amine impregnated mesoporous silica (SBA-15) at wide range pressure and temperature conditions," International Journal of Greenhouse Gas Control, vol. 43, pp. 22-32, 2015.

[5] R. Dawson, A. I. Cooper, and D. J. Adams, "Nanoporous organic polymer networks," Progress in Polymer Science, vol. 37, no. 4, pp. 530-563, 2012.

[6] N. A. Rashidi, S. Yusup, and B. H. Hameed, "Kinetic studies on carbon dioxide capture using lignocellulosic based activated carbon," Energy, vol. 61, pp. 440-446, 2013. 